\title{
Posverdad y exposición selectiva a fake news. Algunos ejemplos concretos de Argentina
}

\author{
Juan Alberto Clavero \\ Universidad Nacional de Lomas de Zamora, Argentina \\ clavero.juan@gmail.com
}

Recibido: 28/2/2018 / Aceptado: 19/4/2018

doi: 10.26439/contratexto2018.n029.1857

REsumen. Este trabajo se enmarca en el debate sobre la posverdad y el impacto
de las fake news en el periodismo y las audiencias. Pero no solo eso, sino que
busca comprender este fenómeno desde una perspectiva sociocultural, más
allá del entorno periodístico. En este contexto, la posverdad no puede ser con-
siderada como una serie de eventos individuales inconexos, sino que debe ser
pensada como un fenómeno que atraviesa el debate público actual, tal como
lo mostró el último escándalo de Cambridge Analytica y Facebook, y la utili-
zación de algoritmos que pueden llegar a generar un alto grado de opacidad
en la información. Este trabajo, por último, también refleja la multiplicación y
fragmentación de las formas en que las mentiras se propagan y perpetúan en
el caos de la comunicación contemporánea.

Palabras clave: posverdad / audiencias / noticias falsas / desinformación / consumo de redes sociales / sitios de noticias falsas 


\title{
Post-Truth and Selective Exposure to Fake News. Some Specific Examples of Argentina
}

\begin{abstract}
This work is part of the debate about post-truth and the impact of fake news in journalism and audiences. We also aim to understand this phenomenon from a socio-cultural perspective, beyond the journalistic environment. In this context, post-truth cannot be considered as a series of unrelated individual events but must rather be thought of as a phenomenon that goes through the current public debate, as shown by the latest Cambridge Analytica and Facebook data scandal, and the use of algorithms that may generate a high degree of obscurity in information. Finally, this paper also reflects the multiplication and fragmentation of the ways in which lies spread and perpetuate amidst the chaos of contemporary communication.

Keywords: post-truth / audiences / fake news / misinformation / social media consumption / fake news sites
\end{abstract}


Comencemos por la desaparición de lo real.

JEAN BAUdRILLARD (2009)

\section{Introducción}

$\mathrm{D}$ esde que el Oxford Dictionary declaró en el 2016 a la posverdad como la palabra del año, esta ha sido objeto de muchas definiciones e interpretaciones (Amado, 2017; Allcott y Gentzkow, 2017; Anderson, Bell y Shirky, 2014, etcétera), las cuales buscan comprender la naturaleza y el alcance de este fenómeno, que involucra tanto a periodistas como a las audiencias y la comunidad, en general. La caracterización de posverdad como "palabra del año" no solo marca el interés por un término atractivo, sobre todo a partir de las elecciones presidenciales en Estados Unidos y la salida del brexit, sino que también muestra un anclaje más profundo: se trata de un fenómeno sintomático de las preocupaciones sobre el estado y estatuto de la verdad en las sociedades contemporáneas, en el contexto de nuevas formas de propaganda y engaño que se ven facilitadas por la revolución digital (Waisbord, 2018).

En efecto, las condiciones de producción y de consumo de información están en cambio constante, y el ciclo de vida de las noticias resulta cada vez más corto: lo que se publica un día a la mañana puede perder su valor noticioso esa misma tarde. Además, la llegada y consolidación de internet trajo aparejada una explosión de información, tanto si consideramos la cantidad como la velocidad de circulación de las noticias. En este sentido, retomando la idea de Waisbord (2018), la posverdad no debe caracterizarse solamente como una distorsión deliberada, noticias falsas y hechos alternativos, es decir, como la producción intencional de falsedades para engañar al público. No se trata solo de eso, sino de que posverdad -en el contexto de la comunicación "posverdad" - pone al descubierto el colapso del modelo racionalista moderno, esto es, de un modelo bien definido y aceptado de decir la verdad como una empresa comunicativa compartida basada en la razón y la ciencia (Waisbord, 2018, p. 19).

Pero debemos señalar otra complejidad: la comunicación posverdad también muestra la ausencia de condiciones en la esfera pública para que los ciudadanos acuerden objetivos y normas procesales para determinar la verdad, como aquello que puede considerarse como afirmaciones verificables sobre la realidad. Esta dificultad exhibe dos fuentes de convergencia:

- Por un lado, la mentada crisis de los medios tradicionales (Amado y Rincón, 2015; Aguado y Castellet, 2013; García, López de Ayala, y Catalina, 2013, etcétera), que repercute en diferentes dimensiones de la profesión periodística: desde la estructura del negocio y la lógica empresarial (Anderson, Rainie y Albright, 2017) hasta el vínculo con las audiencias. 
- Por otro lado, la proliferación de internet alteró de tal manera las condiciones de producción y circulación de la información que cualquier afirmación sobre la verdad y la realidad puede hacerse pública, llegar a audiencias amplias y obtener gran atención en la web, sin que por ello sea necesariamente "verdadero" o comprobable.

Aquí es donde los conceptos de posverdad y fake news han adquirido relevancia en los últimos tiempos. Aunque, como dice Boczkowski (2017), "las noticias falsas han existido durante mucho tiempo, el elemento diferenciador que las propicia es una infraestructura de información con una escala, un alcance y una horizontalidad en los flujos informativos sin precedentes en la historia". $\mathrm{Y}$ esto es posible porque las condiciones de accesibilidad para hacerse oír y amplificar la información son mucho más laxas y permeables que en el pasado, al mismo tiempo que al público le cuesta más detectar información tendenciosa o directamente falsa. En tiempos de fake news, pero también de sitios y periodistas que realizan fact checks, vemos que la tarea de la verificación de hechos presenta serias limitaciones, ya que, según estudios recientes (Guess, Nyhan y Reifler, 2018, p. 1), algunas personas tienden a preferir, cuando les dan a elegir, aquella información que congenia con sus posturas ideológicas más allá de la veracidad de las mismas. Por lo tanto, la veracidad no siempre sería un elemento decisivo a la hora de inclinarse a consumir y compartir una noticia.
Pero, a las dificultades para detectar información tendenciosa o fake news, se suma el comportamiento de los individuos en su dietética de noticias falsas: son consideradas como un complemento y no como sustitutas de las "noticias duras" - hard news- (Guess et al., 2018, p. 5), por lo que pareciera que esta práctica se enfoca en lograr una especie de reaseguro emocional de la posición tomada en el consumo de información.

El cambio en el consumo de información no es otra cosa que el reverso de la alteración en los modos de producción y circulación de las noticias. Ahora las audiencias se entremezclan cada vez más en todos los aspectos de las noticias, ya que pueden convertirse en fuentes que publican por su cuenta o en grupos que pueden crear y analizar datos fuera del alcance de los profesionales, etcétera. Y este cambio no es otra cosa que el emergente de un escenario cultural complejo:

- Una circulación de la información cada vez más veloz. En este contexto, los medios tradicionales deben adaptarse a esta velocidad de desplazamiento de las noticias para no perder audiencias en este flujo permanente.

- Una incipiente dependencia del contenido compartido de los medios tradicionales, pero con el limitante de no siempre contar con una política y una infraestructura orientada a la autenticación de la información circulante. Esto termina afectando la calidad de la información y permeabiliza la circulación de noticias falsas o no completamente comprobadas. 


\section{Posverdad: su materialización en Argentina}

Más allá de sus cristalizaciones particulares, la posverdad presenta una morfología general interesante:

Por un lado, es ubicua, característica que se arroga de los soportes y plataformas por donde circula, y no por pretensiones de universalidad (una de las cualidades de la verdad moderna).

Por otro lado, es una configuración narrativa de un hecho que puede ser o no cierto, pero que tiene un potencial significativo desde lo afectivo para interpelar a determinadas audiencias, y ahí es donde reside su fuerza de interpelación y convocatoria.

No se trata de si las declaraciones específicas representan o retuercen con precisión la realidad, ni tampoco de eventos particulares y tendencias específicas que sugieren el eclipse de un mejor momento para la verdad, sino de que la posverdad implica una nivelación de oportunidades para hacer que cualquier declaración sobre la realidad pueda considerarse potencialmente creíble.

La posverdad, entonces, renuncia a las pretensiones de objetividad y previsibilidad modernas. Pero también se deshace de prácticas más cercanas y menos filosóficas: los nuevos modos sociales de distribución de noticias y comentarios centralizados en los usuarios han terminado por agregar más capas a la comunicación pública. Las redes sociales han devenido en plataformas centrales para la expresión pública, lo que ha desagregado a los públicos en esferas compartimentadas, cada una con sus propios rasgos identitarios y hábitos de circulación y distribución de información (por ejemplo: grupos cerrados de Facebook, grupos de WhatsApp, listas en Twitter, etcétera).

En el estudio de Guess et al. (2018), se puede observar la complejidad en las relaciones entre las audiencias, los medios tradicionales y los sitios de fake news. Durante las elecciones presidenciales en Estados Unidos, el 27,4 \% de los americanos de 18 años o más visitó algún sitio pro-Clinton o pro-Trump de fake news. Pero estos datos se tornan más significativos cuando, de las personas encuestadas que se muestran propensas a visitar sitios web de fake news a favor de su candidato preferido, solo el $63 \%$ afirma tener una visión "muy" o "algo favorable" de sitios o páginas que se dedican a la verificación de los hechos (pp. 5-10), lo que expresa un relativo interés por la veracidad de la información.

En Argentina, y tal vez en América Latina, no contamos con estudios de la envergadura del antes citado. Pero llevar adelante un análisis de contenidos nos permitirá reconstruir algunos procesos de construcción y circulación de fake news tanto en Facebook como en Twitter, las redes que funcionan como fuentes privilegiadas de información (Anderson et al., 2017; también WebFoundation, 2018). Así, este trabajo analiza algunas fake news que circularon en el último tiempo en Argentina. Uno de los motivos de recolectar posts en Facebook y Twitter es identificar la manera como los algoritmos que utilizan estas redes 
pueden desencadenar un alto grado de opacidad en torno a información y actividades que son cruciales para la comunidad, como, por ejemplo, el acceso a servicios y el debate público.

En este contexto, el análisis de caso provee la flexibilidad para estudiar el fenómeno de la posverdad desde diferentes perspectivas y plataformas, y no desde la influencia de una sola variable (que sería el algoritmo utilizado por las redes). Entre estas múltiples variables, tenemos, por ejemplo, el contexto socioeconómico en el que se producen las fake news, recursos gráficos y narrativos; las cuentas y los usuarios que las producen, etcétera.

Además, permite identificar la amplitud de registros (visuales, narrativos, escritos, entre otros) que pueden componer una noticia falsa: desde imágenes anacrónicas, pero absolutamente posibles, hasta el anuncio de cambios climatológicos severos en un contexto de aumento de las tarifas de servicios. El análisis realizado es post facto, ya que la recolección de datos se realizó con posterioridad a los hechos y noticias; e incluso evidenció la cristalización de una fake new a partir de una publicación que la desmentía. Asimismo, admite un manejo más flexible de datos heterogéneos y no siempre replicables, pero que, en su conjunto, nos dan una visión más clara sobre el tema. Por último, el estudio de caso habilita a establecer hipótesis sobre características intrínsecas y contextuales de producción y circulación de fake news que alimenten un posterior estudio cuantitativo.

\section{Las diferentes maneras de construir fake news}

La comunicación pública ha pasado de la comunicación masiva piramidal a flujos de noticias, información y conversación en múltiples niveles. En el orden actual, la propagación a gran escala de fake news no está exclusivamente controlada ni operada por Estados, medios, etcétera, sino que también puede ser producto de usuarios o grupos de usuarios dispuestos a utilizar las facilidades el ecosistema digital para propagar noticias falsas. Tal como señala Waisbord (2018), "desde los actores organizados hasta los ciudadanos comunes, una gama de fuerzas sociales participan con entusiasmo o distracción en distorsionar hechos y perpetuar falsedades" (p. 22).

El primer ejemplo corresponde al tratamiento de la ley de la reforma previsional en Argentina y la construcción de posverdad a través de imágenes. El gobierno de Mauricio Macri impulsó la reglamentación de la reforma previsional que, finalmente, sería aprobada el 19 de diciembre del 2017². En los días previos a la sanción de la ley, la

1 Uno de los cambios más significativos introducidos por la ley fue la modificación de la fórmula que rige el aumento a los jubilados, además de la asignación universal por hijo (AUH) y las 
comunicación por parte del gobierno de llevarla a las cámaras fue recibida por la ciudadanía como un plan de ajuste del sistema previsional. Este aspecto, junto a niveles de inflación que el gobierno no ha logrado equilibrar, provocó un malestar generalizado que terminó en movilizaciones de organizaciones sindicales, sociales, de izquierda, del kirchnerismo, pero que también reunió multitudes no partidarias en contra de este proyecto de ley.

El 13 de diciembre del 2017, se llevó a cabo una gran movilización de los sectores que se oponían al proyecto, los cuales marcharon hacia el Congreso para repudiar la medida que quería implementar por aquel entonces el oficialismo. Esto sucedió en un clima de tensión que finalizó con la represión por parte de la gendarmería y por desmanes por parte de algunos de los sectores movilizados. En esas fechas, las redes sociales se consolidaron como "una segunda arena" en la cual se disputaban las posiciones políticas, donde la generación y propagación de fake news también cumple un rol en el intento de suscitar predisposiciones anímicas en las audiencias involucradas.

\section{Las manifestaciones y las imágenes falsas}

En la figura 1, se puede observar una publicación en la que se narra la historia de un supuesto jubilado que pierde su negocio y su medio de vida a causa de los desmanes llevados a cabo por miembros de la agrupación Quebracho (organización política que estuvo presente en la marcha del día 14 de diciembre del 2017). La vinculación de la foto a un presunto acto de violencia por parte de los manifestantes parece activar un pico de interacción con la publicación, puesto que al momento de la descarga de la red exhibía 1334 reacciones y llevaba compartida casi 33000 veces.

La composición de la noticia presenta varios elementos que trabajan en la construcción de un relato que busca emocionar al lector. No solo eso; el hecho de depender de algoritmos en la curaduría y distribución del contenido significa que publicaciones sociales y políticas cruciales que se encuentren fuera de los parámetros de distribución "diagramados" por las redes pueden no mostrarse a algunos usuarios. Esto quiere decir que dos usuarios con perfiles e intereses

pensiones. Hasta la votación de esta ley, las jubilaciones se modificaban dos veces al año (en marzo y en septiembre) por la llamada "ley de movilidad jubilatoria", aprobada en el 2008, que tomaba variables como los recursos de la Administración Nacional de Seguridad Social (ANSES) y los ingresos de los trabajadores formales para aumentar los haberes jubilatorios. La misma fórmula se aplicaba para incrementar otras pensiones y la asignación universal por hijo. 
similares pueden no estar expuestos a las mismas noticias, pero sí a la misma noticia falsa. Esto sería como si dos personas compraran un mismo periódico impreso, pero descubrieran que se han suprimido diferentes conjuntos de historias de sus ejemplares.

\section{Figura 1. Rolando Otero}

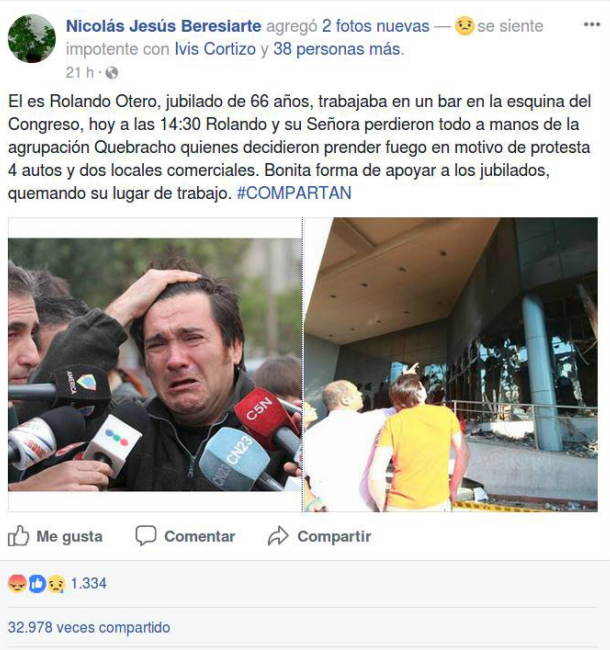

Fuente: Captura de pantalla (Gamarnik, 15 de diciembre del 2017)

En la figura 2, se observa la imagen en su contexto original. Fue publicada en el mes de agosto, pero del año 2012, y corresponde a una persona lamentando la pérdida de un familiar en un episodio de inseguridad. La comprobación de la falsedad de la noticia exhibe un menor potencial de viralización: tiene 100 "me gusta" y fue compartida 213 veces. Esta secuencia de fotos y posts muestra un ápice de la composición de las dietas informativas personalizadas que hoy se encuentran fuera del ámbito de control de los usuarios, lo que termina generando el riesgo de exacerbar las divisiones entre las comunidades de

Figura 2. "Velan los restos del jubilado..."

POPULAR provincia politica policiales deportes espectáculos teono

\section{Velan los restos del jubilado asesinado frente a sus nietos en una entradera}

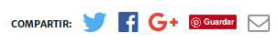

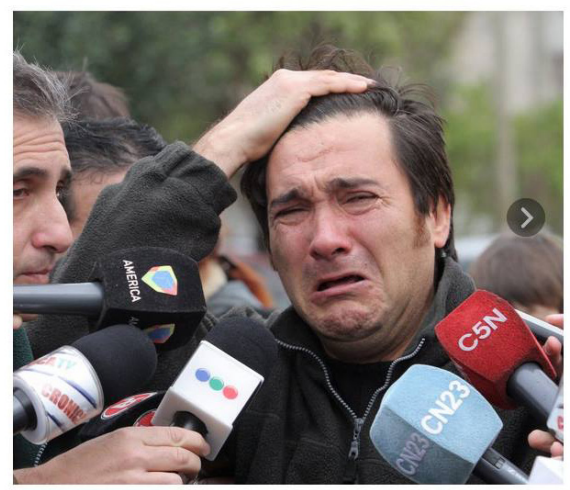

Fuente: Captura de pantalla del Diario Popular ("Velan los restos del jubilado asesinado frente a sus nietos en una entradera", 2012)

manera creciente, sin una base común de noticias ni, por tanto, de una realidad compartida.

En la figura 3, la fotografía reproduce una escena posible. Fue tomada por el fotógrafo Enrique García Medina en diciembre del 2001, en Argentina, durante la represión ejercida por el gobierno de Fernando de la Rúa, que terminaría con 39 muertos y la huida en helicóptero del entonces presidente. 
Figura 3. Fotografía tomada por Enrique García Medina

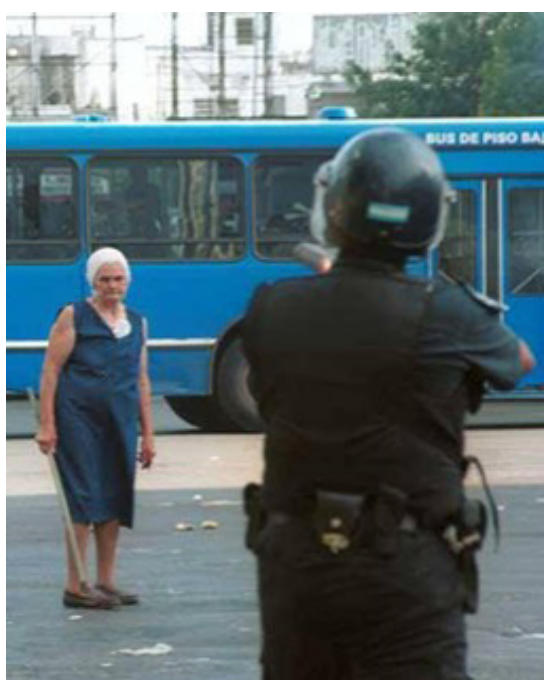

Fuente: Captura de pantalla (Gamarnik, 14 de diciembre del 2017)

Esta imagen circuló como una versión más de la marcha del 14 de diciembre del 2017, como un intento de mostrar la agresividad de las fuerzas policiales. Fue compartida 340 veces al momento de su recolección para este informe.

\section{El cambio climatológico y la subida de impuestos como disparadores de fake news}

La información sobre el supuesto “invierno más crudo de los últimos 15 años" circuló por redes sociales y fue replicada por varios medios. A mediados de marzo del 2018 se difundieron notas $\mathrm{y}$ posts en las redes sociales que aseguraban que el invierno de este año sería el más frío de los últimos 15 años.
Según la página de fact checking Chequeado.com (Slipczuk, 2018), el primer sitio en subir esta (falsa) información fue la página Código Abierto Metán. De acuerdo con la herramienta CrowdTangle (que mide el alcance de los contenidos), el artículo superó las 320000 interacciones en Facebook. Luego esta información sería replicada por diversos sitios, aunque posteriormente algunos de ellos borrarían el registro de esas entradas.

La hipótesis sobre el surgimiento y propagación de esta noticia tiene que ver más con el contexto político que con cuestiones estacionales o ecológicas. Aparece en medio de un incipiente aumento en las tarifas de los servicios básicos en Argentina. Entonces, una noticia con un aparente origen científico, que parece señalar la inevitabilidad del

Figura 4. El invierno que se avecina será el más crudo de los últimos 15 años El Invierno que se avecina será el más crudo de los
últimos 15 años.

\section{Hace 4 dias CLIMA ff Compartir $322 \mathrm{mil}$}

Tanto para Cuyo, como para Catamarca, La Rioja, Salta, Jujuy, Santa Fe, Capital Federal, gran parte del Centro y Oeste de Buenos Aires, San Luis, Córdoba, La Patagonia, todo sera gélido desde mediados de Abril. En la Costa Atlántica se esperan ventiscas congelantes y una sensación térmica de no más de $-7^{\circ}$ bajo cero con un $90 \%$ de probabilidad de nieve.

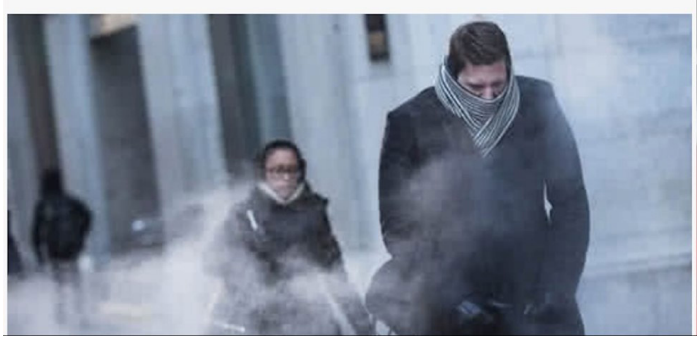

Fuente: Captura de pantalla ("El invierno que se avecina será el más crudo de los últimos 15 años", 2018) 
advenimiento del invierno más frío, se inserta en un escenario de cierta sensibilidad social por el aumento de precios. Finalmente, el semblante pseudocientífico de la noticia pareciera funcionar como un caballo de Troya de una emocionalidad aún mayor.

El 20 de marzo del 2018, el Servicio Meteorológico Nacional publicó una nota en todas sus redes desmintiendo esta teoría sobre el invierno más crudo de los últimos años. Este check fue compartido 4422 veces, dato que pareciera señalar el interés por desmentir una "noticia falsa" que no solo evocaba implicancias climatológicas, sino también sociopolíticas.

Lo que estas secuencias de fotos pretenden mostrar es que la posverdad combina elementos ficcionales y emocionales que trabajan de manera sinérgica para ser "noticiables" y adquirir un rango de verosimilitud lo suficientemente potente como para circular como una posible versión de la realidad. Y, más aún, la comprobación de su inautenticidad suele tener menos potencia emotiva que su circulación, ya que termina siendo un contenido efímero, como la mayoría de los que circulan en las redes.

Además de esta secuencia contextual, estos ejemplos también revisten otras características propias de las fake news, a saber:

\section{Figura 5. El Servicio Meteorológico Nacional} responde a la noticia viral

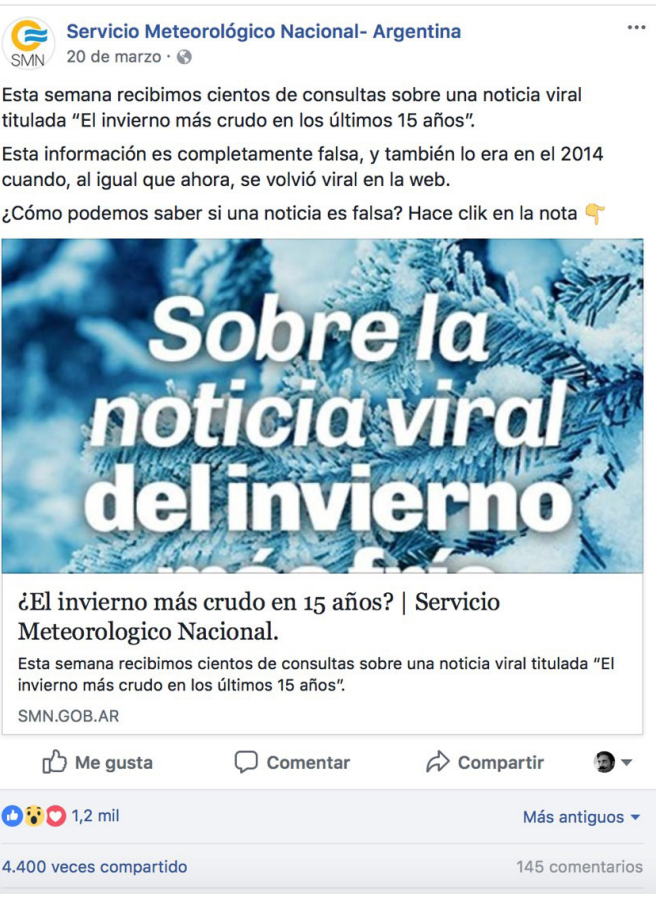

- Uno de los rasgos más distintivos de las noticias citadas es la intención de generar un estado de ánimo particular en la audiencia por sobre la veracidad de los hechos objetivos, la cual, en el contexto de las noticias falsas, acaba siendo lo menos importante. Trabajos como el de Webfoundation (2018, p. 7) y el de Kiderra (2012) presentan el friend factor como un atributo con un peso significativo al momento de marcar cierta 
movilización subjetiva a un mensaje político o social determinado ${ }^{2}$.

- Mucha de la información proferida en las páginas de Facebook de las que surgen estos ejemplos es el resultado de métodos de recolección propios de esta era de redes sociales, en las que no se presta demasiada atención a la veracidad y consistencia de la fuente (Alonso, 2017, p. 78).

- Con las redes sociales se acentúan los perfiles de partisanos (Guess et al., 2018, pp. 5-10), lo que suele causar que los defensores de cada una de las posturas se encierren sobre sí mismos y consuman aquellas noticias falsas que sean consistentes con su postura ideológica (Guess et al., 2018; Alonso, 2017).

Así, pareciera configurarse otra característica propia de las fake news en esta era de la posverdad: la creación de contenidos movilizantes (agresivos, sensibilizantes, etcétera), provocativos, aunque con ciertos rasgos de verosimilitud (podemos volver al ejemplo de las figuras 1 y 2), en los cuales la postura del artículo sea identificable con facilidad. De esta manera, se vuelven compartibles y viralizables por los usuarios (Rehm, 2018).
El recorrido de este trabajo busca recolectar ejemplos que permitan visualizar un estado de situación respecto al impacto de las fake news no solo en el ámbito periodístico, sino también con respecto a su arraigo en dinámicas socioculturales. En efecto, afirmar que el periodismo transmite una representación veraz de la realidad suena, al menos, anticuado. Hoy, la credibilidad pública del periodismo no está ligada exclusivamente a las nociones convencionales de profesionalismo, es decir, como aquella práctica que observa ciertos procesos y normas, y tiene como objetivo producir relatos integrales e imparciales de la realidad (Waisbord, 2006), sino que la credibilidad pareciera jugarse en un terreno más líquido y amorfo: el de las expectativas de las audiencias, las cuales están moldeadas por diferentes variables, como creencias partidistas, ideológicas y, por qué no, la red social por la que están circulando.

Así, el fenómeno de las "noticias falsas" no solo revela portales de noticias de múltiples niveles y la imposibilidad del periodismo tradicional de controlar el espolón de noticias, información y rumores, en un entorno sin puerta, sino que también es indicativo de la existencia de contratos diferentes entre las

2 El experimento llevado a cabo por Fowler y sus colegas consistía en asignar a 600000 usuarios de Facebook un mensaje informativo en el día de las elecciones presidenciales de Estados Unidos; otros 600000 fueron los destinatarios de un mensaje social; y, finalmente, los que no vieron nada. Uno de los resultados de este estudio concluyó que aquellos usuarios que recibieron el mensaje social se mostraron más permeables a buscar un lugar de votación y hacer clic en el botón "He votado". 
organizaciones de noticias y los lectores (Waisbord, 2018, p. 23).

\section{Conclusión}

Este artículo buscó comprender y ofrecer algunos ejemplos sobre los mecanismos de difusión de noticias falsas y la efectividad de las respuestas a estas. Vimos que Facebook desempeña un papel importante al propagar y viralizar este tipo de información, al mismo tiempo que funciona como señuelo para dirigir a las personas a sitios web de noticias falsas.Estos elementos nos permiten entrar de lleno en el debate sobre la posverdad, ya que este concepto/mecanismo pone en evidencia la crisis de la relación entre el periodismo, las audiencias y la sociedad civil. En este contexto, el periodismo parece no encontrar su lugar de relevancia en el diálogo permanente que los ciudadanos tienen consigo mismos y con las instituciones.

Este problema no se resolverá con la simple adquisición de una cultura digital por parte de los medios, sino entendiendo de qué manera las audiencias reclaman, leen y comparten información en la actualidad. Implica un esfuerzo por traspasar la seducción del engagement para lograr una cultura de la relevancia. En este entorno, los medios de comunicación tradicionales pierden terreno, prolifera la información sin garantía de fiabilidad, la frontera entre hechos y opiniones está cada vez más difuminada y la ética profesional disminuye. Esto redunda en un escenario crítico para el periodismo y los periodistas. Como dice Bokova (2017):
[E]l increíble enmarañamiento actual de los medios informativos modifica las funciones tradicionales de los productores, difusores y consumidores de información. La profusión de noticias falsas o trucadas (fake news), así como el riesgo de que el público quede aprisionado en "burbujas de información" creadas mediante algoritmos, abren nuevos interrogantes sobre la libertad de expresión y la diversidad cultural.

Para poder seguir pensando el alcance y la influencia de la posverdad, debemos ser capaces de pensar más allá de ella. Pensar en un orden subvertido donde, por ejemplo, quienes antes eran categorizados como audiencia, hoy son nodos de generación y distribución de contenidos e información relevante para sus contactos. Para comprender la posverdad, resulta pertinente plantearse las condiciones actuales de producción de las noticias, la cual ya no está en manos solo de profesionales, sino también de cualquier persona, incluso de una machine learning.

Se trata, entonces, de un desplazamiento, del paso de un paradigma donde las ideas se imparten de manera vertical a una concepción más horizontal, donde cada punto es un centro nodal de recepción, pero también de interpretación y distribución de información. En ella, los medios de comunicación no deben mostrarse ajenos a la necesidad de una mayor transparencia como mecanismo para ganar credibilidad en un entorno donde se está redefiniendo el contrato social del periodismo con las audiencias. 


\section{Referencias}

Aguado, J., y Castellet, A. (2013). Periodismo móvil e información ubicua. En J. Aguado, C. Feijóo e I. Martínez (Coords.), La comunicación móvil. Hacia un nuevo ecosistema digital (pp. 187-217). Barcelona: Gedisa.

Allcott, H., y Gentzkow, M. (2017). Social Media and Fake News in the 2016 Election. Journal of Economic Perspectives, 31(2), 211-236. doi:10.1257/jep.31.2.211

Alonso, P. (2017). Fake news y posverdad en tiempos de populismos: lecciones para periodistas. Cuadernos de Periodistas, 34, 77-84. Recuperado de http://www.cuadernosdeperiodistas.com/media/2017/07/Patricia_Alonso-1.pdf

Amado, A. (2017). Los periodistas latinoamericanos en el siglo xxi: más allá del debate de la posverdad. Contratexto, 27, 17-38. doi:10.26439/contratexto.2017.027.001

Amado, A., y Rincón, O. (2015). La reinvención de los discursos o cómo entender a los bárbaros del siglo xxi en la comunicación en mutación. En A. Amado y O. Rincón (Eds.), La comunicación en mutación (pp. 5-12). Bogotá: Fundación Friedrich Ebert (FES).

Anderson, C. W., Bell, J. E., y Shirky, C., (2014). Post Industrial Journalism: Adapting to the Present. Nueva York, NY: Columbia University Academic Commons.

Anderson, J., Rainie, L., y Albright, J. (2017). The Future of Free Speech, Trolls, Anonymity, and Fake News Online. Pew Research Center. Recuperado de http:// www.pewinternet.org/2017/03/29/the-future-of-free-speechtrolls-anonymityand-fake news-online/

Baudrillard, J. (2009). ¿Por qué todo no ha desaparecido aún? (Trad. G. Villalba). Buenos Aires: Libros del Zorzal.

Boczkowski, P. (2017). La posverdad. Revista Anfibia. Recuperado de http://www.revistaanfibia.com/ensayo/la-postverdad/.

Bokova, I. (2017). Editorial de Unesco Courier. Recuperado de https://es.unesco.org/ courier/2017-julio-septiembre/editorial-irina-bokova

El invierno que se avecina será el más crudo de los últimos 15 años. (2018). Código abierto Metán. Recuperado de http://codigoabiertometan.com/noticias/id-14139_ El-Invierno-que-se-avecina-ser-el-m-s-crudo-de-los-ltimos-15-a-os-

Gamarnik, C.(14dediciembre del2017).Sin título [entrada en Facebook]. Recuperado de https://www.facebook.com/photo.hp?fbid=1660632273989159\&set=pb.100001 272071791.-2207520000.1519608319.\&type=1\&theater

Gamarnik, C. (15 de diciembre de 2017). Des-mintiendo [entrada en Facebook]. Recuperado de https://www.facebook.com/photo.hp?fbid=1662284370490616\& set=pb.100001272071791. -2207520000.1519608062 . \&type=3\&theater 
García, A., López de Ayala, M. C., y Catalina, B. (2013). The Influence of Social Networks on the Adolescents' Online Practices. Comunicar, 41, 195-204. http:// dx.doi.org/10.3916/C41-2013-19

Guess, A., Nyhan, B., y Reifler, J. (2018). Selective Exposure to Misinformation: Evidence from the Consumption of Fake News during the 2016 US Presidential Campaign. Exeter: Department of Politics.

Kiderra, I. (12 de septiembre del 2012). Facebook Boosts Voter Turnout. UC San Diego News Center. Recuperado de http://ucsdnews.ucsd.edu/pressrelease/facebook_ fuels_the_friend_vote

Rehm, G. (2018). An Infrastructure for Empowering Internet Users to Handle Fake News and Other Online Media Phenomena. En G. Rehm y T. Declerck (Eds.), Language Technologies for the Challenges of the Digital Age. GSCL 2017. Lecture Notes in Computer Science, 10713 (pp. 216-231). Cham: Springer. https://doi. org/10.1007/978-3-319-73706-5_19

Servicio Meteorológico Nacional de Argentina. (20 de marzo del 2018). El invierno más crudo en los últimos 15 años... [entrada de Facebook]. Recuperado de https://www.facebook.com/SMN.ar/posts/1817991638253628

Slipczuk, M. (22 de diciembre del 2018). Es \#FalsoEnLasRedes que este será el invierno más frío de los últimos 15 años [mensaje en un blog]. Recuperado de http:// chequeado.com/el-explicador/es-falsoenlasredes-que-este-sera-el-inviernomas-frio-de-los-ultimos-15-anos/

Velan los restos del jubilado asesinado frente a sus nietos en una entradera. (22 de agosto del 2012). Diario Popular [captura de pantalla]. Recuperado de https:// www.diariopopular.com.ar/policiales/velan-los-restos-del-jubilado-asesinado-frente-sus-nietos-una-entradera-n127249

Waisbord, S. (2006). In Journalism We Trust? Credibility and Fragmented Journalism in Latin America. En K. Voltmer (Ed.), Mass Media and Political Communication in New Democracies (pp. 76-91). Londres: Routledge.

Waisbord, S. (2018). The Elective Affinity between Post-Truth Communication and Populist Politics. Communication Research and Practice, 4(1), 17-34. doi:10.1080/22 041451.2018.1428928

Webfoundation. (2018). La mano invisible, el newsfeed de Facebook y nuestra dieta informativa. Recuperado de https://webfoundation.org/research/the-invisible-curation-of-content-facebooks-news-feed-and-our-information-diets/ 